\title{
Wheat seedlings traits as affected by soaking at titanium dioxide nanoparticles
}

\author{
Adel A. Shafea, Mona F. Dawood*, Mohamed A. Zidan \\ Assiut University, Botany and Microbiology department, Assiut University, 71516 Assiut, Egypt
}

Received: 12 October 2016

Accepted: 21 January 2017

Published online: 7 March 2017

\begin{abstract}
The recent advances in nanotechnology and its use in the field of agriculture are astonishingly increasing; therefore, it is important to understand their role in plant life. Four wheat cultivars soaked in different concentrations of TiO2-NPs $(0.0 \%, 0.025 \%, 0.05$ $\%, 0.1 \%, 0.2 \%$ and $0.5 \%$ ) to select a concentration that stimulate cultivars growth under normal conditions during germination stage. Cultivar dependency appeared markedly in their response to TiO2-NPs. Generally, TiO2-NPs did not modify germination percentage, despite $0.1 \%$ TiO2-NPs vastly enhanced seed potential by increasing vigor index, root dry matter stress tolerance index, shoot dry matter stress tolerance index, dry matter stress tolerance index, plant height stress tolerance index, root length stress tolerance index, fresh matter stress tolerance index and pigment composition. The surrounding concentrations exert little effect on the studied parameters and $0.5 \%$ TiO2-NPs suppressed all indices.
\end{abstract}

Keywords: $\mathrm{TiO}_{2}$, NPs, wheat, germination, seed potential

\section{Introduction}

There is now an extensive debate about the risks and benefits of the many manufactured nanomaterials into the environment (USEPA 2007) and in order to evaluate their potential adverse effects on the ecosystems and on human health, the scientific community is working with increasing attention to this topic. Numerous nanoparticles have been investigated for their potential application in agriculture including nano-silver, nano-silica, nano-aluminium, nano-zinc oxide, nano-copper, carbon nano tubes and nano-titanium dioxide. Currently, nanoparticles are produced from a large variety of bulk materials (Brunner et al. 2006), with broad industrial applications including biomedicine and biotechnology; hence it is to be expected that these particles will find their way into various ecosystems (Behra and Krug 2008).Titanium dioxide is used commercially as the most appropriate catalyst for photo-catalytic reactions; upon exposure to ultraviolet light it mineralizes the organic chemicals in rivers to water and carbon dioxide with the potential to destroy microorganisms (Owolade et al. 2008). $\mathrm{TiO} 2-\mathrm{NPs}$ have been proposed as an additive to plant protection product to reduce their half-lives. TiO2NPs can shield the active substance of a plant protection product from radiation; thus, prevent plant protection product sensitive to sunlight from photo-catalytic degradation (Gogos et al. 2012). TiO2NPs has also been proposed as a photo-protective constituent shielding leaf surfaces from UV light,

* Corresponding author: Mona F. Dawood

e-mail: mo_fa87@yahoo.com 
Shafea et al.

thereby reducing sunburn damage of leaves. Other possible applications pose the use as dispersing agent and even fertilizer for spinach (Gogos et al. 2012). Application of nanoparticles can also increase seed germination and seedling growth because nanoparticles can facilitate enhanced ability of water and fertilizer absorption by roots (Morteza et al. 2013).

In Egypt, wheat crop is considered the first strategic food crop, since it constitutes the major part of the Egyptian diet (Zaki and Radwan 2011). It has maintained its position as the basic staple food in urban areas and mixed with maize in rural areas for bread making. In addition, wheat straw is an important fodder (Gaballah and Mandour 2000; Zaki and Radwan 2011). Egypt represents the world's biggest wheat buyer, so attempts should be done to increase wheat production and fill the gap between consumption and production. Various ways had been used to increase wheat productivity such as newly developed technology of application of nanoparticles.

The role of TiO2-NPs on pigment activation directed the research to find out the optimal concentration of TiO2-NPs promoting pigment content thereby increasing all grains value parameters of different wheat cultivars at germination stage.

\section{Materials and Methods}

\subsection{Cultivars selection}

Four wheat cultivars, two durum wheat cultivars "cv. Benisuif 5 and cv. Sohag 3" obtained kindly from Agriculture Research Centre of Shandwell and other two cultivars are bread wheat "cv. Sakha 93 and cv. Seds 12" were kindly brought about from breeding program - Faculty of agriculture - Assiut University, were used in this study.

\section{2. $\mathrm{TiO}_{2}-\mathrm{NPs}$ suspension preparation}

TiO2-NPs suspension was prepared by dispersing TiO2-NPs powder in bi-distillated water and sonicated with ultrasound sonicator (Ultrasonic Cleaners, Bronson, USA) twice for $30 \mathrm{~min}$. prior to exposure experiments (Mahmoodzadeh et al. 2013).

\subsection{Culture technique}

Grains of the cultivars (cv. Seds 12, cv. Sakha 93, cv. Sohag 3 and cv. Benisuif 5) were surface sterilized with sodium hypochlorite (5\%) or 10 minutes. 10 grains were placed in disinfected petri dishes provided with filter paper. $10 \mathrm{ml}$ of freshly prepared $\mathrm{TiO}_{2}$-NPs suspension $(0.025 \%, 0.05 \%, 0.1 \%$, $0.2 \%$ and $0.5 \%$ ) were applied to different petri dishes and control plants were soaked in distilled water. Four replicates were used for each treatment. All of the petri dish kept at $20 \pm 10^{\circ} \mathrm{C}$ for 15 days and the following measurements were done.

\section{Germination percentage (GP)}

Germination percentage $=$ Number of germinated seeds $/$ Number of total seeds $\times 100$

\section{Vigor index}

The vigor index of seedlings was calculated with the following equation (Dahindwal et al. 1991):

Vigor index $=($ shoot length + root length $) \times$ germination percentage $/ 100$.

\section{Seedling growth stress indices parameters}

Roots and shoots were separated and used for recording the parameters. Total length of root and shoot was measured and expressed in $\mathrm{cm}$. Their fresh weights were measured and then were dried 
Shafea et al.

for two days at $80^{\circ} \mathrm{C}$ and dry weight was taken and expressed in grams. Then used for determination of PHSI, RLSI, SDSI, RDSI, DMSI and FMSI according to (Nawaz 2014).

PHSI $(\%)=[$ Plant height of stressed plant $/$ plant height of control plant $] \times 100$

RLSI $(\%)=[$ Root length of stressed plant/ root length of control plant $] \times 100$

FMSI $(\%)=[$ Fresh matter of stressed plant $/$ fresh matter of control plant $] \times 100$

DMSI $(\%)=[$ Dry matter of stressed plant/ dry matter of control plant $] \times 100$

SDSI $(\%)=[$ shoot dry weights of treated plants/ shoot dry weights of control plants $] \times 100$

RDSI $(\%)=[$ root dry weights of treated plants/ root dry weights of control plants $] \times 100$

\subsection{Photosynthetic pigments}

The fractions of pigments (chlorophyll a, chlorophyll $b$ and carotenoids) were estimated using the spectrophotometric method recommended by (Lichtenthaler 1987). The photosynthetic pigments were extracted from $0.05 \mathrm{gm}$ fresh leaf sample suspended in $5 \mathrm{ml}$ of $95 \%$ ethyl alcohol, then heating at $60-70^{\circ} \mathrm{C}$ in water bath, until colorless. The total volume was completed to $10 \mathrm{ml}$ with $95 \%$ ethyl alcohol and absorbance readings were followed with a spectrophotometer (Unico UV- 2100 spectrophotometer) at 663, 644 and $452 \mathrm{~nm}$. Chlorophylls and carotenoids concentrations were calculated as $\mathrm{mg} / \mathrm{g}$ FW.

\subsection{Statistical analysis}

The data of each cultivar were subjected to one- way ANOVA using SPSS 10.0 software program. Means were calculated for three replicate values for each trait. Means were compared by the Duncan's multiple range tests and statistical significance was determined at $5 \%$ level.

\section{Results}

\subsection{Germination percentage}

The data in figures 1 revealed that germination percentage did not change whatever the cultivar tested or the concentration of $\mathrm{TiO}_{2}$-NPs applied.

\subsection{Vigor index}

Figures 1 present; the bi- physic effect of $\mathrm{TiO}_{2}$-NPs on vigor index along the concentration gradient used. Vigor index promoted gradually as $\mathrm{TiO}_{2}-\mathrm{NPs}$ concentrations increased in soaking media where maximal values was recorded at $0.1 \%$, but with different values by $32.91 \%, 52.63 \%, 16.33 \%$ and $45.26 \%$ for cv. Seds 12, cv. Sakha 93, cv. Sohag 3 and cv. Benisuif 5, respectively. The reverse trend was recorded at $0.2 \%$ and $0.5 \% \mathrm{TiO}_{2}-\mathrm{NPs}$ where the concentrations of $\mathrm{TiO}_{2}-\mathrm{NPs}$ nonsignificantly affect vigor index for cv. Sakha 93 and cv. Sohag 3, induced some increase by $12.44 \%$ for cv. Benisuif 5 and significantly reduced it for cv. Seds 12. Otherwise, the concentration of $0.5 \%$ $\mathrm{TiO}_{2}$-NPs reduced vigor index for most cultivars except for $\mathrm{cv}$. Benisuif 5 .

\subsection{Plant height and root length stress tolerance index (PHSI and RLSI)}

The studied cultivars responded similarly to $\mathrm{TiO}_{2}$-NPs what PHSI and RLSI demonstrated in Figures 1 that the maximal PHSI and RLSI were recorded at the level of $0.1 \% \mathrm{TiO}_{2}-\mathrm{NPs}$ where maximal increase of both indices was observed for cv. Sakha 93 by approximate $62.5 \%$ and $40.91 \%$ respectively and minimal response was recorded for $\mathrm{cv}$. Sohag 3 with increase of 15.79 and $16.67 \%$ in comparison to control, respectively. 


\subsection{Shoot and root dry matter stress tolerance index (RDSI, SDSI and DMSI)}

As evident from the data in figures 1; the cultivars varied considerably in their response to the different concentrations of $\mathrm{TiO}_{2}$-NPs applied.

In cv. Seds 12 and cv. Sakha 93: The two cultivars exhibited three situations in their response to $\mathrm{TiO}_{2}$-NPs: The doses $0.025 \%$ and $0.2 \%$ induced non- significant change in RDSI, SDSI and DMSI. Whilst the doses $0.05 \%$ and $0.1 \%$ stimulated RDSI, SDSI and DMSI, but much more so for the dose $0.1 \%$. Also, cv. Sakha 93 exhibited the highest response compared to cv. Seds 12. In cv. Seds 12, the percent increase of RDSI, SDSI and DMSI was $39.43 \%, 57.31 \%$ and $46.85 \%$ and that of cv. Sakha 93 was $31.56 \%, 126.39 \%$ and $63.38 \%$, respectively. on the other hand, the highest dose of $\mathrm{TiO}_{2}-\mathrm{NPs}$ $(0.5 \%)$ exerted reduction rather than stimulation of the RDSI, SDSI and consequently DMSI, but much more so for cv. Seds 12 .

In cv. Sohag 3: most of the studied doses exhibited insignificant change of RDSI, SDSI and DMSI except for the concentration of $0.1 \%$ which enhanced these indices by $22.27 \%, 20.91 \%$ and $21.63 \%$, respectively, whilst the dose of $0.5 \%$ significantly reduced RDSI, SDSI and DMSI in relation to control.

In cv. Benisuif 5: the range of the studied $\mathrm{TiO}_{2}-\mathrm{NPs}$ concentrations discriminated stimulation of RDSI, SDSI and DMSI, but maximally at the dose of $0.1 \%$ which stimulated these indices by 48.64 $\%, 113.45 \%$ and $75.24 \%$ respectively. It should be emphasized that the dose of $0.5 \%$ induced nonsignificant increase in dry matter production.

\subsection{Fresh matter stress tolerance index (FMSI)}

The effect of grains soaking with different levels of $\mathrm{TiO}_{2}$-NPs on FMSI was analyzed and demonstrated in figures 1 . At the level of $0.1 \%$, the increase of FMSI was $36.27 \%$ for cv. Seds 12 , $84.18 \%$ for cv. Sakha 93, $62.71 \%$ for cv. Benisuif 5 and $13.9 \%$ for cv. Sohag 3. The highest dose of $\mathrm{TiO}_{2}$-NPs $(0.5 \%)$ had inhibitory effect on FMSI of all the tested cultivars except for cv. Benisuif 5 which reported non- significant change of FMSI. On the other hand the lowest doses generally did not modify the trend of FMSI except for $\mathrm{cv}$. Benisuif 5 where some stimulation was recorded.

\subsection{Pigmentation}

Data expressing the content of photosynthetically active pigments under different concentrations of $\mathrm{TiO}_{2}$-NPs for the cultivars tested (Figures 2). Noticeably, the level of $0.1 \%$ had stimulatory effect on pigmentation of the four studied cultivars. But the magnitude of stimulation exhibited varying degrees depending on cultivar that the percent increase in chlorophyll a, chlorophyll b, carotenoids and total pigments for cv. Seds 12 was $22.74 \%, 44.20 \%, 28.57 \%$ and $28.19 \%$; for cv. Sakha 93 was $44.53 \%, 31.71 \%, 54.17 \%$ and $46.64 \%$; for cv. Sohag 3 was $25 \%, 20.83 \%, 32.86 \%$ and $27.53 \%$ and that for cv. Benisuif 5 was $40.56 \%, 46 \%, 71.15 \%$ and $52.19 \%$ respectively. Nonsignificant increase was recorded for the concentrations of $\mathrm{TiO}_{2}-\mathrm{NPs}_{\text {amounting }}(0.025 \%, 0.05 \%$ and $0.2 \%$ ) except for $\mathrm{cv}$. Benisuif 5 which induced significant increase in the pigments. On the other hand, the highest concentration of $\mathrm{TiO}_{2}$-NPs $(0.5 \%)$ recorded significant reduction of the studied pigments in all cultivars except for non-significant increase in the studied pigments in cv. Benisuif 5. 
Shafea et al.

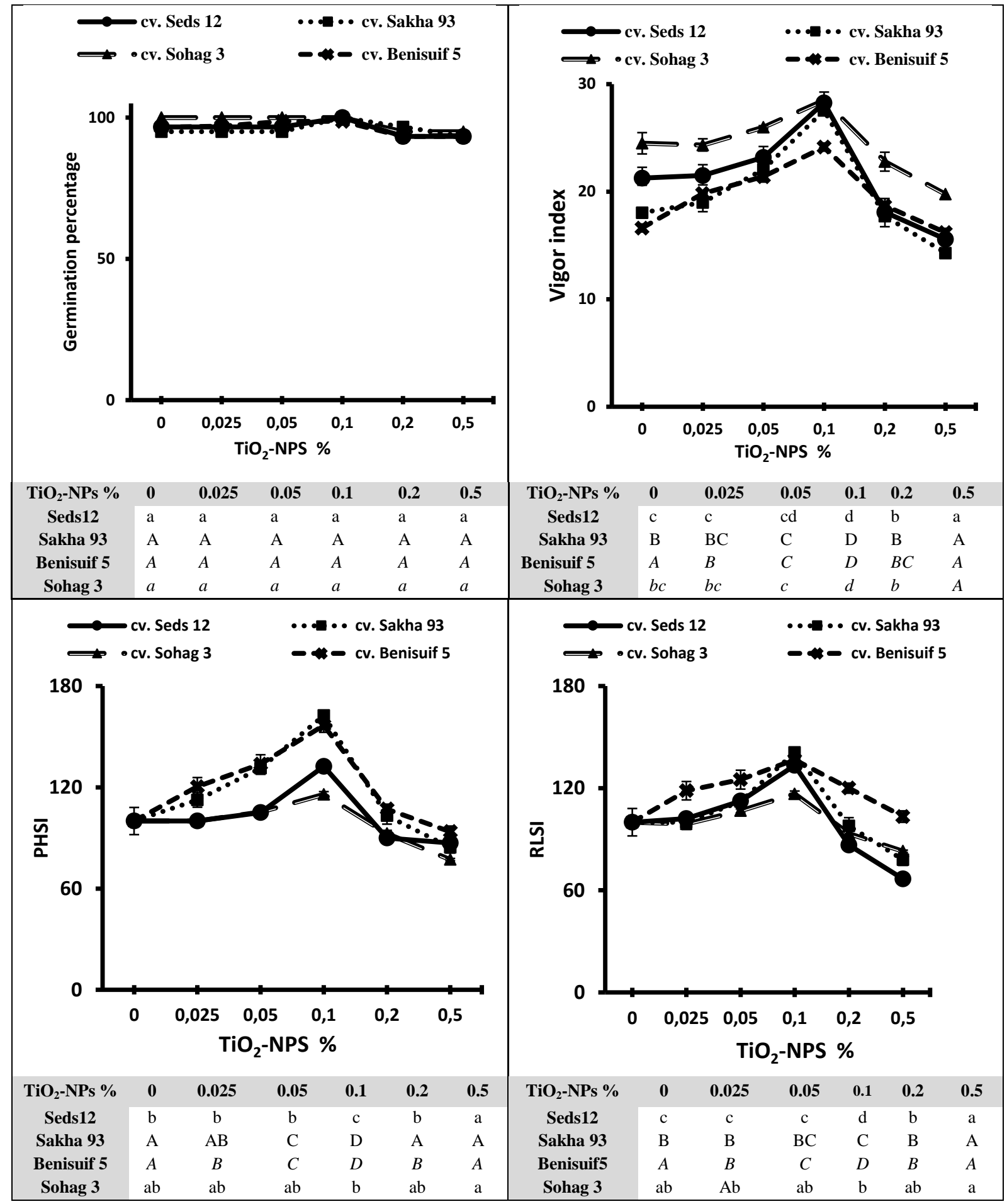

Fig. 1A Germination percentage, vigor index, plant height stress index (PHSI), root length stress index (RLSI) of wheat cultivars grain under different concentrations of TiO2-NPs. Each value represents a mean of three replicates + SE. different letters are significantly different at $\mathrm{P}<0.05$. 
Shafea et al.

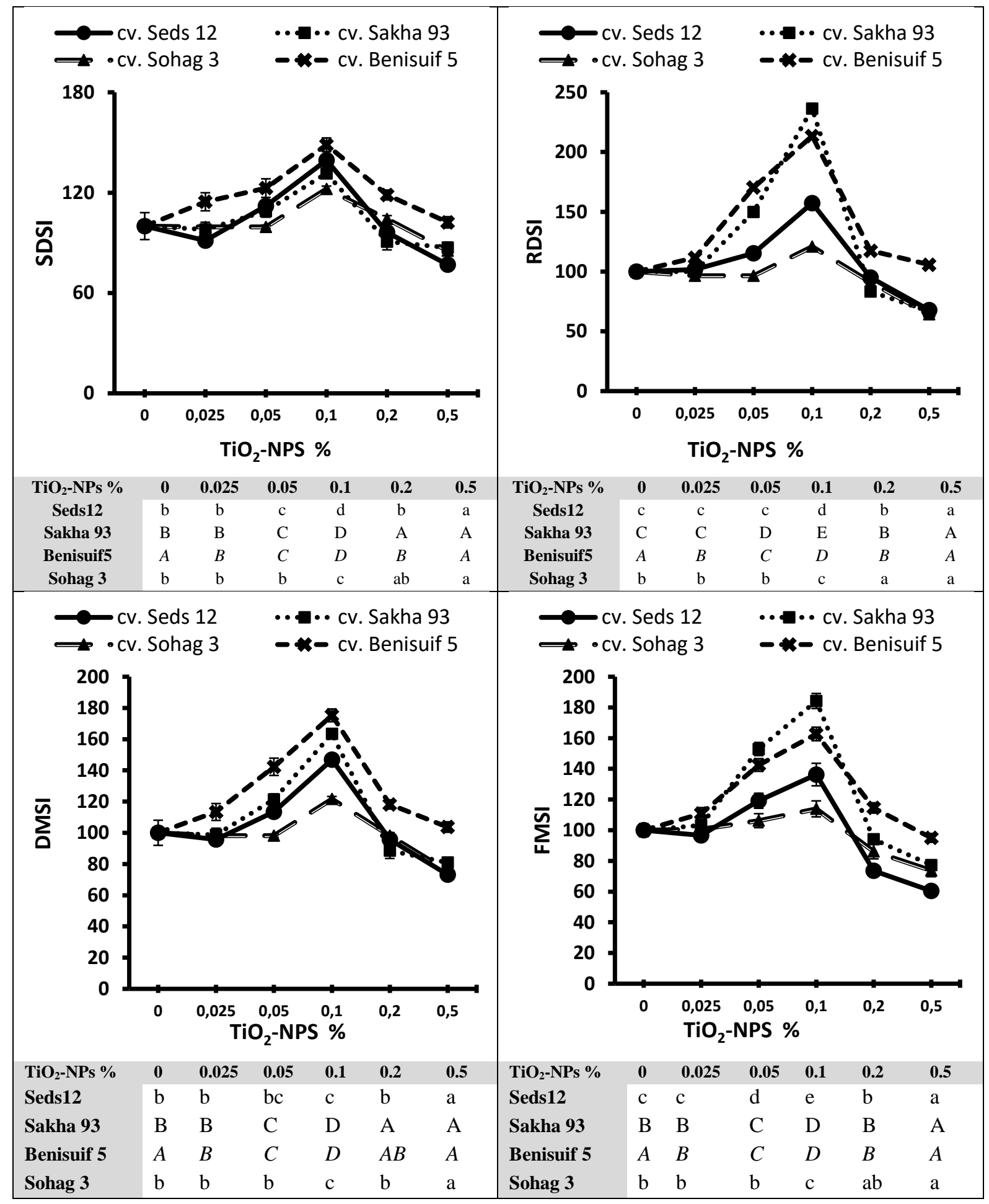

Fig. 1B Shoot dry matter stress index (SDSI), root dry matter stress index (RDSI), dry matter stress index (DMSI) and fresh matter stress index (FMSI) of wheat cultivars grain under different concentrations of TiO2-NPs. Each value represents a mean of three replicates + SE. different letters are significantly different at $\mathrm{P}<0.05$. 

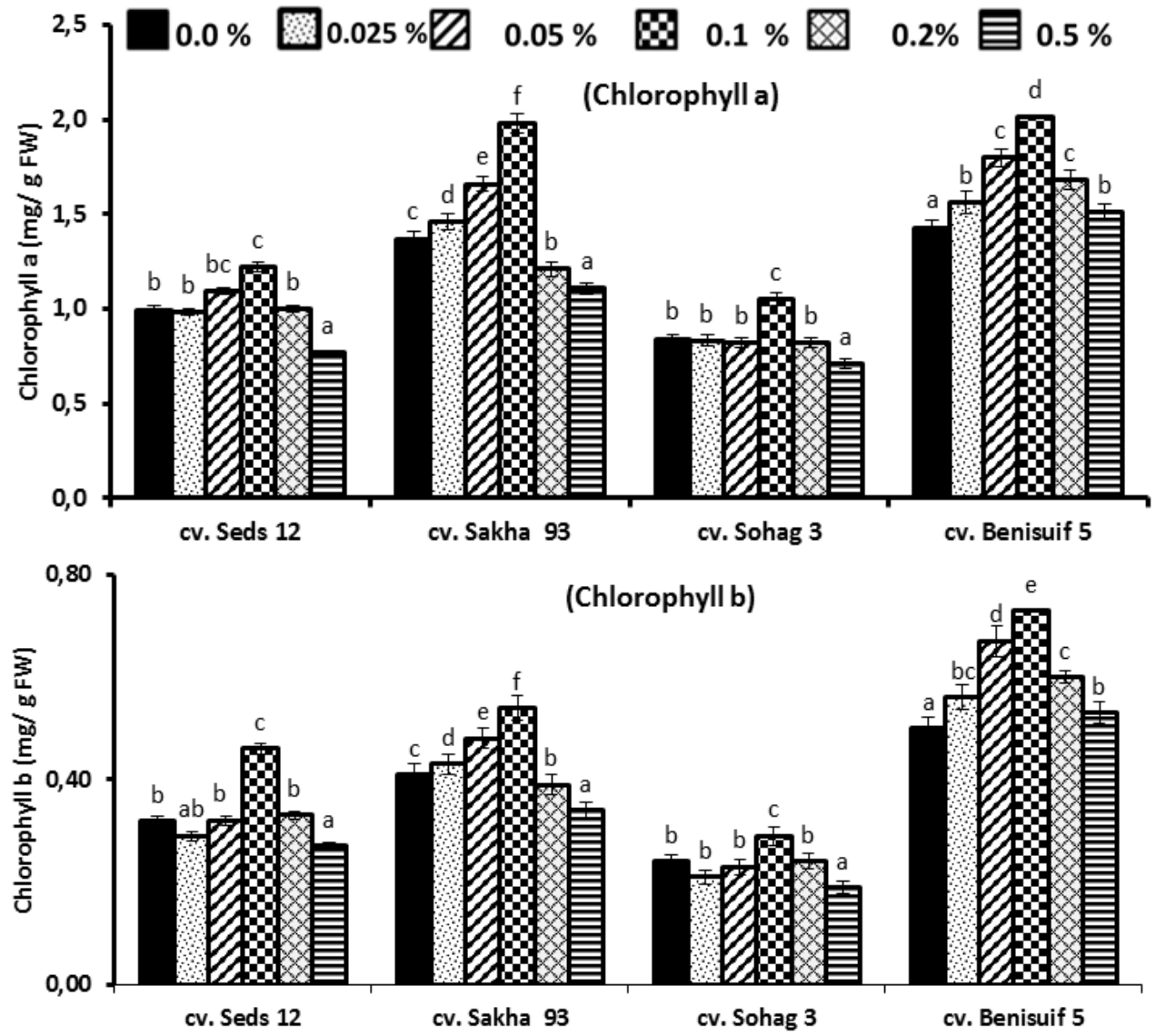

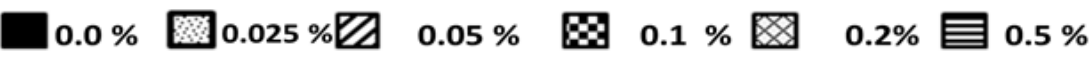
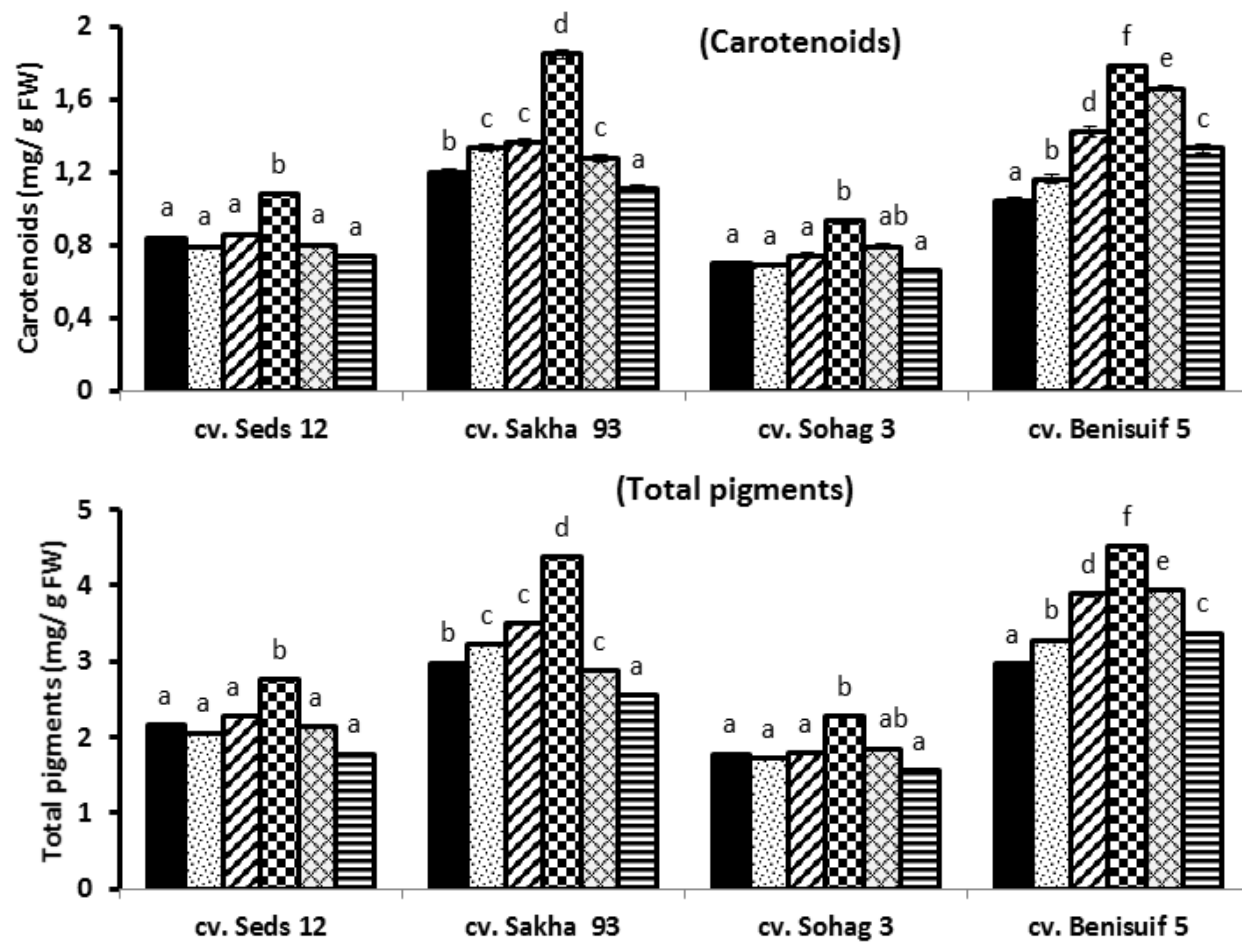

Fig. 2 Chlorophyll a, chlorophyll b, carotenoids and total pigments of wheat cultivars grain under different concentrations of $\mathrm{TiO}_{2}$-NPs. Each histogram represents a mean value of three replicates $\pm \mathrm{SE}$. Different letters are significantly different at $P<0.05$. 


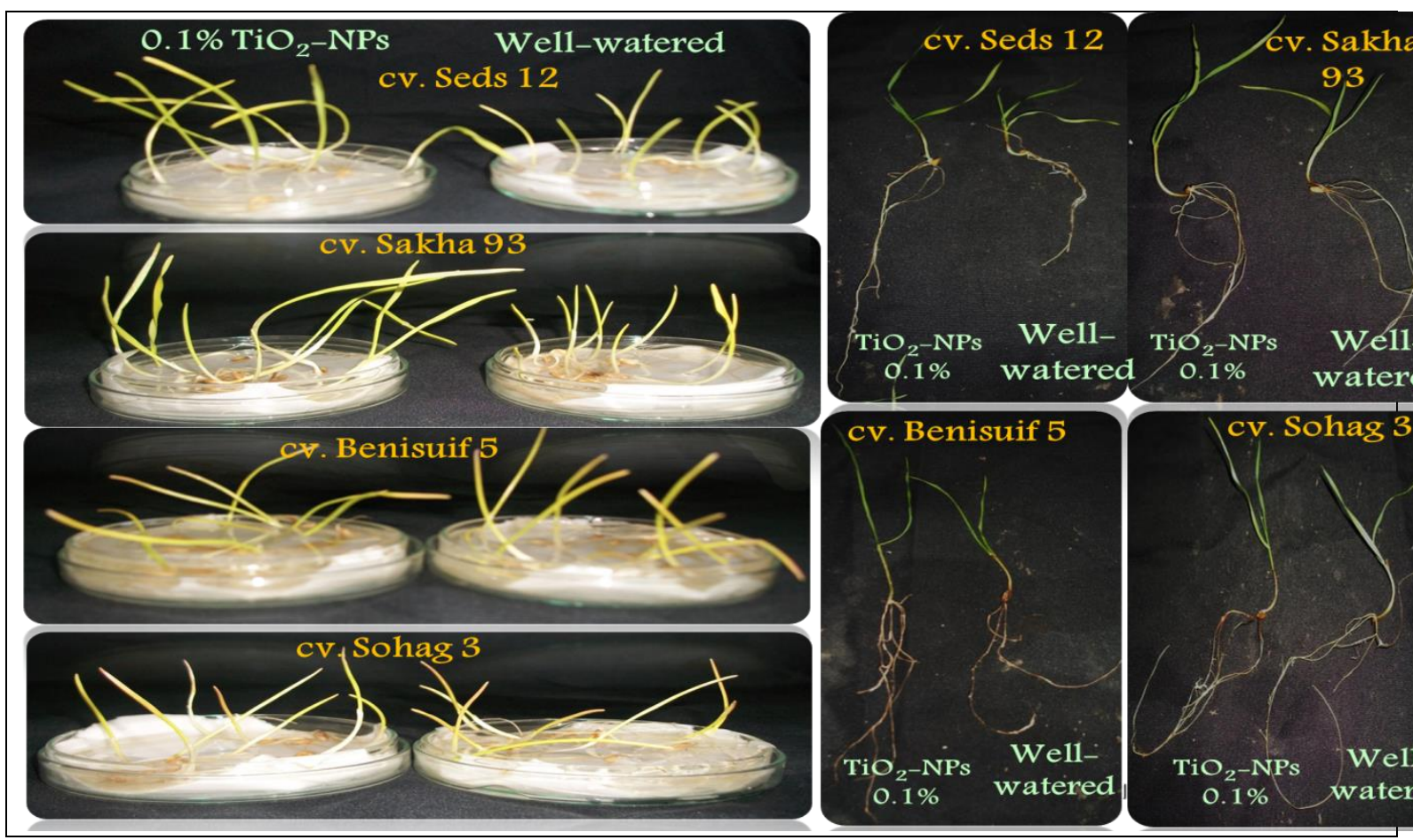

Fig. 3 Wheat cultivars grain soaked under $0.1 \% \mathrm{TiO}_{2}$-NPs.

\section{Discussion}

As we know seed germination provides a suitable foundation for plant growth, development and yield, so well establishment of potential seedlings help producing vigor plants able to endure climatic changes. In the present experiment application of TiO2-NPs doses mediated bi-physic effect on the studied indices that the concentrations of TiO2-NPs $(0.025 \%, 0.05 \%$, and $0.2 \%)$ induced nonsignificant change in the entire criteria except for $\mathrm{cv}$. Benisuif 5 that recorded stimulation of the last studied indices (vigor index, root dry matter stress tolerance index, shoot dry matter stress tolerance index, dry matter stress tolerance index, plant height stress tolerance index, root length stress tolerance index, fresh matter stress tolerance index and pigment composition). The concentration $0.1 \%$ TiO2-NPs discriminated maximal stimulation of growth criteria in all the tested cultivars. On the other hand, the highest concentration of TiO2-NPs $(0.5 \% \mathrm{TiO} 2-\mathrm{NPs})$ showed inhibition rather than stimulation of growth parameters except for $\mathrm{cv}$. Benisuif 5 that recorded no change in the studied parameters. The data vastly showed that cv. Sakha 93 exhibited the highest response of all the used criteria, followed by cv. Benisuif 5, then cv. Seds 12 and the lowest response cultivar was cv. Sohag 3. In this respect, Rezaei et al. (2015) found that different concentrations of nano titanium dioxide enhanced soybean height, grain weight, number of pods per plant, pod dry weight, oil percentage and seed and oil yield. However, the mode of action of nanoparticles on plant growth and development is still too little understood and the effect of NPs on plants varies between species. Seed soaking with $0.1 \%$ TiO2-NPs may play a potential protective role in plants under control conditions and its usefulness as fertilizer for plant protection in agriculture, however, is at the same time a possible threat to the terrestrial environment in high dosage (higher than 0.5\% TiO2-NPs at least in the present study). Our results were consistent with Feizi et al., (2012) stated that application of TiO2-NPs at appropriate concentrations improved seedling growth of wheat compared to the bulk and control treatments, whilst high concentrations of TiO2-NPs, have inhibitory effects on the growth of wheat plants. Mahmoodzadeh et al. (2013) reported enhancement of seed germination, radicle and plumule growth of canola seedlings by TiO2-NPs. Hghighi et al. (2012) showed that the use of one mg per liter of titanium, increased fresh and dry weight of shoot compared to the control treatment in tomato plants. The increment of growth with application of TiO2- NPs, 
Shafea et al.

increased compared with the bulk treatment, because of the easier passage of this nanoparticle into the seeds of plant compared with the bulk treatment in spinach (Zheng et al. 2005) as well as nanoparticles can gather nutrients in their surface and act as a nutritional source for the plant (Navarro et al. 2008).

Positive effects of TiO2-NPs stimulator doses on seedling growth was pigment enhancement as recorded notably at $0.1 \% \mathrm{TiO} 2-\mathrm{NPs}$ which may be due to TiO2-NPs act as a photo-catalyst and induce an oxidation-reduction reaction (Crabtree 1998). TiO2-NPs increases light absorbance, accelerate the transport and conversion of the light energy, protect chloroplasts from aging, and prolong the photosynthetic time of the chloroplasts. TiO2-NPs noticeably promotes aged seeds' vigor, chlorophyll formation, stimulates Ribulose 1, 5- bisphosphate carboxylase activity and increases photosynthesis, thereby increasing plant growth and development (Yang et al. 2006). TiO2-NPs protect the chloroplast from excessive light by augmenting the activity of antioxidant enzymes (Hong et al. 2005). Similarly, Lei et al. (2007) as well as Monica and Cremonini (2009) found that TiO2-NPs increased photosynthesis and plant growth in spinach and enhanced absorption and transmission of solar energy to electron energy and chemical active energy. They also found that TiO2-NPs entered the chloroplast and was transferred in the photosynthetic electron transport chain to create NADP+, was reduced to NADPH, and coupled to photophosphorylation and transformed electron energy to ATP. So, TiO2-NPs greatly increased whole chain electron transport, photo-reduction in photosystem II, O2 evolution and photophosphorylation. Moreover, nanoparticles of titanium increase cell growth by improvement of photosynthetic and nitrogen metabolism and therefore, caused an increasing in plant weight (Hong et al. 2005; Mingyu et al. 2007).

\section{Conclusion}

Titanium dioxide nanoparticles $\left(\mathrm{TiO}_{2}\right.$-NPs) are substances should be applied for agriculture with $0.1 \% \mathrm{TiO}_{2}$-NPs stimulated vigorously wheat seedlings traits. The research vastly showed that cv. Sakha 93 exhibited the highest response to $\mathrm{TiO}_{2}$-NPs of all the used criteria, followed by cv. Benisuif 5 , then cv. Seds 12 and the lowest response cultivar was cv. Sohag 3. Soaking wheat grains at selective $\mathrm{TiO}_{2}$-NPs concentration able to enhance active photosynthetic pigments, is superior criteria in improving plant growth especially germination stage which provides a suitable foundation for plant body building.

\section{Abbreviations}

TiO2-NPs= Titanium dioxide nanoparticles, PHSI $=$ plant height stress tolerance index, RLSI $=$ root length stress tolerance index, SDSI= shoot dry matter stress tolerance index, RDSI= root dry matter stress tolerance index, DMSI= dry matter stress tolerance index, FMSI= fresh matter stress tolerance index.

\section{References}

Behra R, Krug H (2008) Nanoecotoxicology-Nanoparticles at large. Nature Nanotechnology, 3: 253 254. doi: 10.1038/nnano.2008.113.

Brunner TI, Wick P, Manser P, Spohn P, Grass R N, Limbach L K, Bruinink A, Stark WJ (2006) In vitro cytotoxicity of oxide nanoparticles: comparison to asbestos, silica, and effect of particle solubility. Environmental Science \& Technology. 40, 4374-4381.

Crabtree RH (1998): A new type of hydrogen bond. Science 282:2000-2001.

Dahindwal AS, Lather BPS, Singh J (1991) Efficacy of seed treatment on germination, seedling emergence and vigor of cotton (Gossypium hirsutum) genotypes. Seed Research, 19: 59-61.

Feizi H, Rezvani Moghaddam P, Shahtahmassebi N, Fotovat A (2012) Impact of bulk and nanosized titanium dioxide (TiO2) on wheat seed germination and seedling growth. Biological Trace Element Research, 146: 101-106. 
Shafea et al.

Gaballah M S, Mandour MS (2000) Increasing drought resistance of wheat plants during grain filling by using chemical desiccants. Journal of Science, Mansoura Univ., 25(2): 833-841.

Gogos A, Knauer K, Bucheli TD (2012) Nanomaterials in plant protection and fertilization: Current state, foreseen applications, and research priorities. Journal of Agriculture and Food Chemistry, 60(39): 9781-9792.

Hghighi M, Heidarian S, Teixeira Silva JA (2012) The effect of titanium amendment in N- withholding nutrient solution on physiological and photosynthesis attributes and micronutrient uptake of tomato. Biological Trace Element Research, 150: 381-90. doi: 10.1007/s12011-012-9481-y.

Hong FH, Yang F, Liu C, Gao Q, Wan ZG, Gu FG, Wu C, Ma ZN, Zhou J, Yang P (2005) Influences of nano-TiO2 on the chloroplast aging of spinach under light. Biological Trace Element Research, 104: 249-260. PMID: 15930594

Lei Z, Mingyu S, Chao L, Liang C, Hao H, Xiao W, Xiaoqing L, Fan Y, Fengqing G, Fashui H (2007) Effects of nanoanatase $\mathrm{TiO} 2$ on photosynthesis of spinach chloroplasts under different light illumination. Biological Trace Element Research, 119: 68-76. doi: 10.1007/s12011-007-8028-0. Epub 2007 Sep 5. PMID: 18186002.

Lichtenthaler HK (1987) Chlorophyll and carotenoids pigments of photosynthetic biomembranes. Methods in Enzymology 148: 350-382.

Mahmoodzadeh H, Aghili R, Nabavi M (2013) Physiological effects of TiO2 nanoparticles on wheat (Triticum aestivum). Technical Journal of Engineering and Applied Sciences, 3 (14): 1365-1370, 2013.

Mingyu S, Fashui H, Chao L, Xiao W, Xiaoqing L, Liang C, Fengqing G, Fan Y, Zhongrui L (2007) Effects of Nano-anatase $\mathrm{TiO} 2$ on absorption, distribution of light, and photoreduction activities of chloroplast membrane of spinach. Biological Trace Element Research, 118: 120-130.

Monica RC, Cremonini R (2009) Nanoparticles and higher plants. Caryologia, 62(2), 161-165.

Morteza E, Moaveni P, Farahani HA, Kiyani M (2013) Study of photosynthetic pigments changes of maize (Zea mays L.) under nano TiO2 spraying at various growth stages. Springer Plus, 2(1): 247. doi: 10.1186/2193-1801-2-247.

Navarro E, Baun A, Behra R, Hartmann NB, Filser J, Miao A, Quigg A, Santschi PH, Sigg L (2008) Environmental behavior and ecotoxicity of engineered nanoparticles to algae, plants, and fungi. Ecotoxicology, 17: 372-386.

See comment in PubMed Commons belowNawaz F (2014) Wheat response to exogenous selenium supply under drought stress (Ph.D. dissertation), University of Agriculture, Faisalabad, Pakistan, 2014.

Owolade OF, Ogunleti DO, Adenekan MO (2008) Titanum dioxide affects diseases, development and yield of edible cowpea. Electronic Journal of Environmental Agricultural and Food Chemistry, 7(5): 2942-2947.

Rezaei F, Moaveni P, Mozafari H (2015) Effect of different concentrations and time of nano TiO2 spraying on quantitative and qualitative yield of soybean (Glycine max L.) at shahr-e-qods, Iran. Biological Forum - An International Journal 7(1): 957-964.

USEPA (2007) Nanotechnology White Paper - External Review Draft.U.S. Environmental Protection Agency. Document no. EPA 100/B- 07/001.

Yang F, Hong F, You W, Liu C, Gao F, Wu C, Yang P (2006) Influence of nano-anatase TiO2 on the nitrogen metabolism of growing spinach. Biological Trace Element Research 110(2): 179-190.

Zaki RN, Radwan TEE (2011) Improving wheat grain yield and its quality under salinity conditions at a newly reclaimed soil by using different organic sources as soil or foliar applications. Journal of Applied Sciences Research, 7(1): 42-55.

Zheng L, Hong F, Lu S, Liu C (2005) Effect of nanoTiO2 on strength of naturally aged seeds and growth of spinach. Biological Trace Element Research, 104: 83-91. pmid:15851835 doi: 10.1385/bter:104:1:083 